\title{
Evaluation of Rutting and Fatigue Behaviors of Asphalt Binders Modified with Calcium Lignosulfonate
}

\author{
Saeed Fatemi $(\mathbb{D}$, Jafar Bolouri Bazaz $\mathbb{D}$, and Seyed Ali Ziaee $\mathbb{i}$ \\ Department of Civil Engineering, Engineering Faculty, Ferdowsi University of Mashhad, Mashhad, Iran \\ Correspondence should be addressed to Jafar Bolouri Bazaz; bolouri@um.ac.ir
}

Received 21 May 2021; Revised 15 August 2021; Accepted 25 August 2021; Published 2 September 2021

Academic Editor: Nikhil Saboo

Copyright (C) 2021 Saeed Fatemi et al. This is an open access article distributed under the Creative Commons Attribution License, which permits unrestricted use, distribution, and reproduction in any medium, provided the original work is properly cited.

\begin{abstract}
Asphalt mixes encounter different distress during the life cycle of asphalt pavements, among which rutting and fatigue failure are prominent. Moreover, the addition of environmentally friendly modifiers into the asphalt binder to increase the performance of asphalt mixes has been a challenging phenomenon for researchers. Calcium lignosulfonate (CL) is a waste material that is a byproduct of the wood industry. In this paper, the impact of the calcium lignosulfonate on the rutting and fatigue performance of the asphalt binder was investigated. For this purpose, the Dynamic Shear Rheometer (DSR) was utilized to run the Multiple Stress Creep Recovery (MSCR) test and evaluate $G^{*} / \sin \delta$ and $G^{*} \cdot \sin \delta$ indices for the asphalt binder containing different percentages of CL. The elastic recovery test was also conducted on the asphalt binder. In order to analyze the thermal storage stability of CLmodified asphalt binders, the storage stability test was considered. The Field Emission Scanning Electron Microscope test showed that using CL as a binder modifier makes the texture of the asphalt binder spongy and porous. The conventional test results indicated that increasing the CL amount in the asphalt binder led to an increase in the stiffness of the asphalt binder. The rheological test results showed that the rutting resistance of the asphalt binder improved by adding up to $15 \%$ of the CL powder; however, the fatigue performance and the elasticity of the asphalt binder declined by increasing the CL content in the asphalt binder. The storage stability test revealed that the dispersion of CL in the asphalt binder was uniform; moreover, the presence of $\mathrm{CL}$ in the asphalt binder could not adversely affect the thermal storage stability of the modified asphalt binder.
\end{abstract}

\section{Introduction}

Calcium lignosulfonate (CL) is an amorphous yellow powder, which is made of wood lignin. Wood lignin is a byproduct of the wood industry that consists of phenylpropane units [1]. Every year, a large amount of lignin waste is produced and disposed of in the world, which causes environmental problems [2]. Therefore, finding a way to reuse this material in the industry is a major concern to the researchers. To this aim, this material is used as an additive in concrete and asphalt mixes. It is shown that the use of this material in the asphalt industry improves some of the performance characteristics of asphalt binder and mixes. In addition, it provides environmental benefits [2, 3]. For example, previous findings showed that the use of biomass materials in the construction process of asphalt mixes lessens the need for harsh chemical materials, which leads to minimizing health risks of humans and reducing chemical pollutions of aquatic environments located near the asphalt pavements $[4,5]$.

In 2013, wood lignin was used as an asphalt binder modifier. For this purpose, $5 \%$ and $10 \%$ of wood lignin were added to two different types of neat and polymer-modified asphalt binder. The rheological properties of the modified asphalt binder were investigated. It was shown that using wood lignin can improve the rutting resistance of the asphalt binder. The improvement was more significant compared with the neat asphalt binder. There was also no significant change in the low-temperature performance of the asphalt binder when modified with the wood lignin compare with the virgin asphalt binder [6]. The antiaging performance of the lignin-modified asphalt binder was investigated in 2017 [7]. Moreover, it was shown that the wood lignin has the potential to substitute a portion of the asphalt binder. Lignin 
modification improved the aging and rutting resistance of the asphalt binder. However, it had an adverse effect on the fatigue performance of the asphalt binder. Another study in 2020 investigated the performance of asphalt binder modified with different percentages of wood lignin [8]. It was shown that using up to $8 \%$ of wood lignin improved the rutting and aging resistance of the asphalt binder, while it did not have any substantial impact on the fatigue performance. An improvement in rutting, aging resistance, and a reduction in the fatigue performance of the asphalt binder containing lignin was reported in another study in 2020 [9].

Arafat et al. showed that the original source of lignin was influential on the physical, chemical, and rheological behavior of the supplied lignin; as an illustration, lignins achieved from different plant materials had various properties of phenylpropanoids [2]. Batista et al. used the kraft lignin supplied from the pulp and paper industries to modify the asphalt binder [10]. The modified specimens exhibited higher rutting resistance at high temperatures. Moreover, lignin could increase the toughness of asphalt binder against thermal cracking at low temperatures. Just like in other studies, McCready and Williams revealed that the presence of lignin within the asphalt binder improved its performance at high temperatures, whereas low-temperature performance degraded slightly [11]. Besides, they found that the dispersion of lignin in the asphalt binder increased its flow activation energy.

It can be seen from the literature that wood lignin as a waste material has a positive effect on the rutting behavior of asphalt binder. There are various types of lignin, namely, organosolv, kraft, klason, enzymatic hydrolyzed, sulfonated, and calcium lignosulfonate (CL) lignin [2]. However, there exists little information about the effect of derivatives of this substance, such as calcium lignosulfonate, on the performance of asphalt binders. Meanwhile, CL has enough potential to be utilized as a plant-based asphalt binder modifier because, on the one hand, CL chemical composition consists of reactive phenolic, hydroxyl, and aromatic groups, which can be used for modification of petroleum chemical products [12]. On the other hand, CL chemical structure has similarities with petroleum bitumen [13]. Therefore, this study was performed to gain a comprehensive understanding of the influence of $\mathrm{CL}$ on the rutting and fatigue properties of the asphalt binders.

\section{Objectives and Scope of Work}

In this paper, first, the physical properties of CL powder and virgin asphalt binder were determined. Meanwhile, chemical components and surface morphology of CL were investigated using XRF and FESEM techniques, respectively. Second, different blends were prepared by dispersion CL into the virgin asphalt binder in the proportions of $5 \%, 10 \%$, $15 \%$, and $20 \%$ by mass of the asphalt binder. Third, conventional binder tests were performed on CL-modified samples, including penetration, softening point, ductility, and kinematic viscosity tests. Finally, the asphalt binder's rutting, fatigue, and elasticity potential were evaluated to study the impact of CL on the asphalt binder's behavior using the Multiple Stress Creep Recovery (MSCR) test and $G^{*} / \sin \delta$ and $G^{*} \cdot \sin \delta$ indices. Figure 1 depicts the flow chart of experiments performed in this study.

\section{Materials and Methods}

3.1. Asphalt Binder. The neat asphalt binder used in this study was $60 / 70$ penetration grade. Some conventional properties of this asphalt binder, such as penetration, viscosity at $135^{\circ} \mathrm{C}$, softening point, and specific gravity, were determined as listed in Table 1. It can be concluded that the asphalt binder physical test results were within the specification limits.

3.2. Calcium Lignosulfonate. The purified calcium lignosulfonate used in this study was supplied from Ligno Tech South Africa Co., Ltd. This product is obtained from sulfite pulping of wood and consists of three alcohols, namely, coniferyl alcohol, p-coumaryl alcohol, and sinapyl alcohol [14]. The chemical components of CL were determined by $\mathrm{X}$-ray fluorescence (XRF) analysis. The mentioned analysis was carried out by the ARL PERFORM'X spectrometer. Table 2 expresses the weight percentage of main oxides based on bulk chemical analysis technique. Moreover, the physical properties of this substance are summarized in Table 3.

3.3. Sample Preparation. To prepare the specimens, 5, 10, 15, and 20 percent of the CL by weight of total asphalt binder were dissolved in virgin asphalt binder (60/70 penetration grade). For this aim, the CL powder was gradually added to the asphalt binder, and the mix was blended using a highshear mixer with the rotational speed of $3000 \mathrm{rpm}$ for 30 minutes at $160^{\circ} \mathrm{C}$. Field Emission Scanning Electron Microscope (FESEM) images were then taken to show the morphology and the texture of the asphalt binder after modification [15]. The test was carried out at the ambient temperature and a scale of $200 \mu \mathrm{m}$. The microscopic pictures of the asphalt binder are presented in Figure 2. As shown in Figure 2, it is clearly visible that the CL influenced the asphalt binder texture after the mixing process. The neat asphalt binder has a smooth surface texture with little distortion. The CL modification has made the asphalt binder texture spongy and porous.

\section{Laboratory Testing Program}

4.1. Conventional Asphalt Binder Tests. Conventional tests present valuable outputs from the physical properties of the asphalt binder, which can be attributed to some performance behavior of asphalt binder [16]. In this research, the effects of CL content on the penetration (AASHTO T49), softening point (AASHTO T 53), ductility (ASTM D113), and kinematic viscosity at $135^{\circ} \mathrm{C}$ (AASHTO T201) were investigated. The viscosity was also measured using the rotational viscosity in accordance with AASHTO T316 at $135^{\circ} \mathrm{C}$ and $165^{\circ} \mathrm{C}$ as compaction and mixing temperatures, respectively. The flow activation energy, which shows the sensitivity of asphalt binder to temperature and its resistance to pumping and 


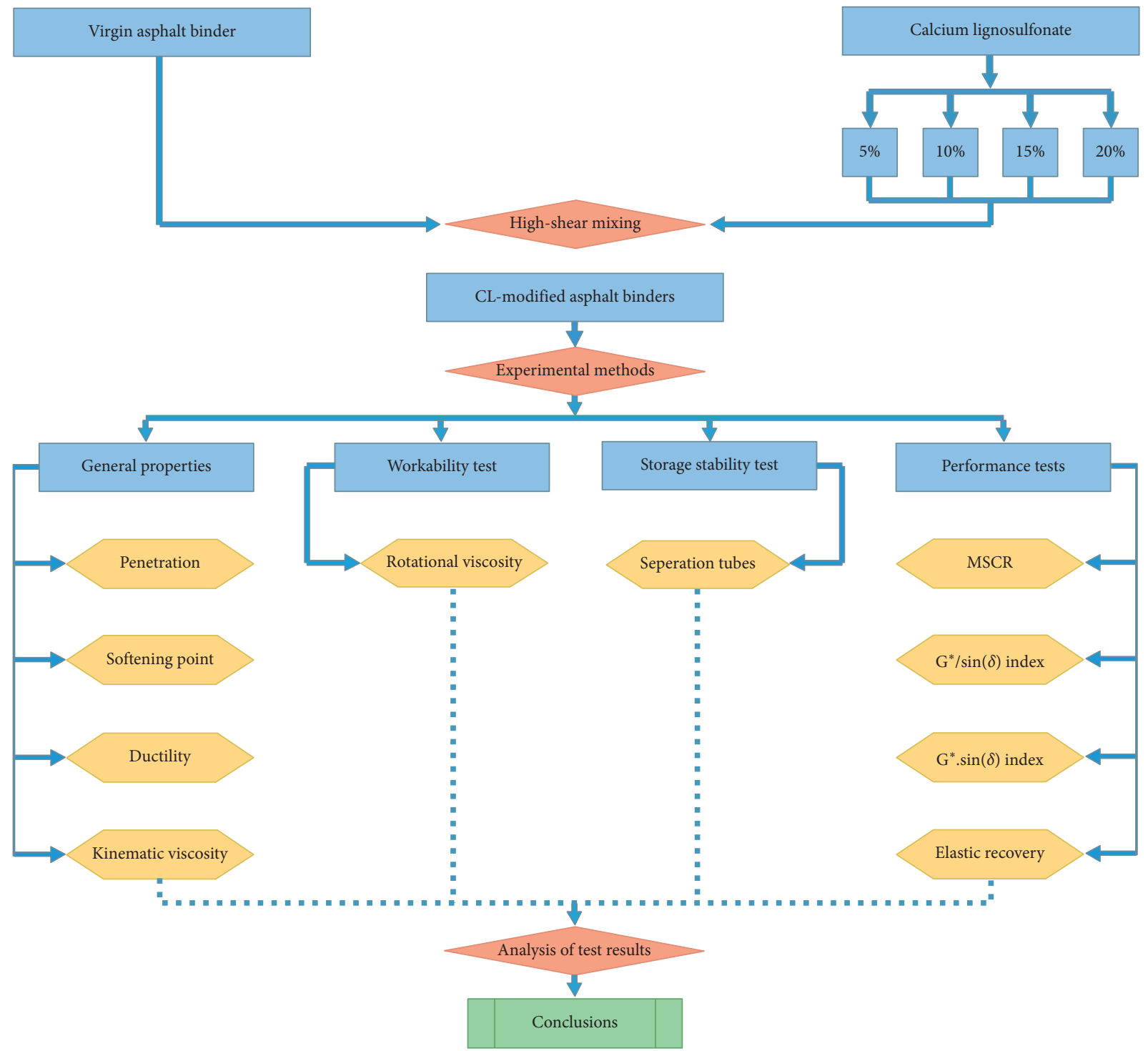

Figure 1: Experimental plan scheme.

Table 1: Physical specifications of the neat asphalt binder.

\begin{tabular}{|c|c|c|c|c|}
\hline Test properties & Unit & Test method & Test result & Specification limits \\
\hline Penetration@ $25^{\circ} \mathrm{C}$ & $(0.1 \mathrm{~mm})$ & ASTM D5 & 66 & $60-70$ \\
\hline Softening point & $\left({ }^{\circ} \mathrm{C}\right)$ & ASTM D36 & 49 & $49-56$ \\
\hline Viscosity@135 $\mathrm{C}$ & $(\mathrm{mPa} \cdot \mathrm{s})$ & ASTM D2170 & 356 & $\geq 300$ \\
\hline Relative density @25 $\mathrm{C}$ & - & ASTM D70 & 1.018 & $1.01-1.06$ \\
\hline Flash point & $\left({ }^{\circ} \mathrm{C}\right)$ & ASTM D92 & 310 & $\geq 232$ \\
\hline
\end{tabular}

TABLe 2: Chemical composition of CL powder.

\begin{tabular}{|c|c|c|c|c|c|c|c|c|c|c|}
\hline Constituent & $\mathrm{Na}_{2} \mathrm{O}$ & $\mathrm{MgO}$ & $\mathrm{K}_{2} \mathrm{O}$ & $\mathrm{SO}_{3}$ & $\mathrm{CaO}$ & $\mathrm{Fe}_{2} \mathrm{O}_{3}$ & $\mathrm{P}_{2} \mathrm{O}_{5}$ & $\mathrm{TiO}_{2}$ & $\mathrm{MnO}$ & LOI $\left(950^{\circ} \mathrm{C}\right)$ \\
\hline Wt (\%) & 0.04 & 0.17 & 0.12 & 2.9 & 8.0 & 0.08 & 0.11 & 0.01 & 0.08 & 88.29 \\
\hline
\end{tabular}


TABLE 3: Physical specifications of calcium lignosulfonate.

\begin{tabular}{lcc}
\hline Test & Unit & Results \\
\hline Color & - & Light brown \\
Dry matter & $\%$ min & 93.0 \\
pH (10\% solution) & - & $\% .5 \pm 0.8$ \\
Insolubility (v/v) & $\% \max$ & 0.5 \\
Bulk density & $\mathrm{kg} / \mathrm{m}^{3}$ & 500 \\
Reducing sugars & $\%$ & 3 \\
\hline
\end{tabular}

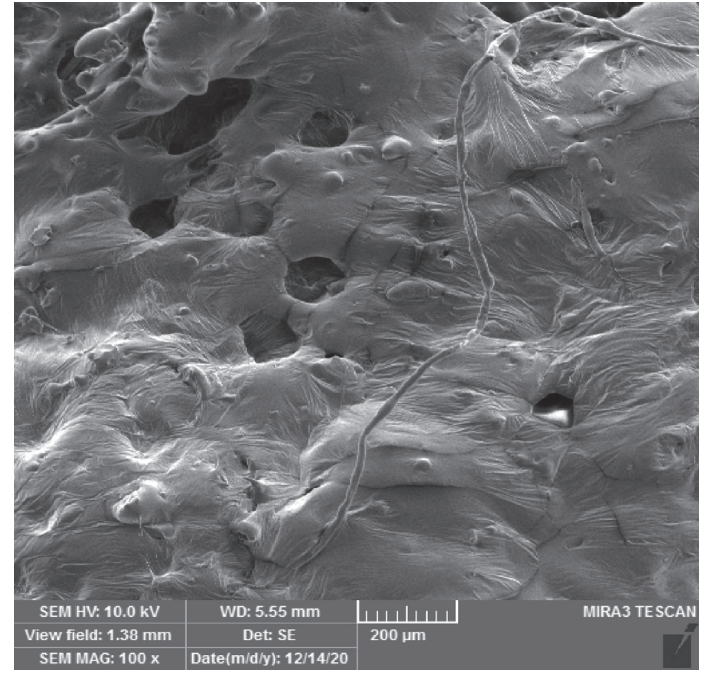

(a)

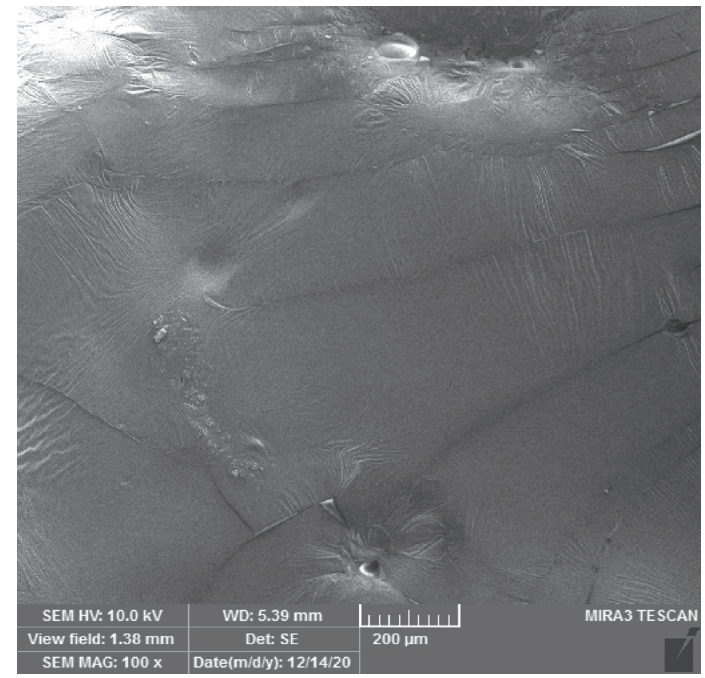

(b)

Figure 2: The FESEM images were taken at 100x zoom of (a) the $20 \%$ CL-modified asphalt binder and (b) the neat asphalt binder.

mixing with aggregates, is calculated using the Arrhenius Equation as follows $[17,18]$ :

$$
\ln \eta=\frac{E f}{(R T)}+\ln A,
$$

where $\eta$ is the asphalt binder viscosity $(\mathrm{Pa} \cdot \mathrm{s}), \mathrm{Ef}$ is the activation energy $\left(\mathrm{kJ} \cdot \mathrm{mol}^{-1}\right), R$ is the universal gas constant, which is equal to $8.314 E-3 \mathrm{~kJ} \cdot \mathrm{mol}^{-1} \cdot \mathrm{K}^{-1}, T$ is the temperature $(\mathrm{K})$, and $A$ is the constant of the equation.

For calculating the $E f$ parameter, at first, the plot of $\ln \eta$ versus $1 / T$ should be depicted. Then, a linear equation should be fitted into the data. Afterward, the slope of the equation will be equal to $E f / R$. Therefore, $E f$ will be calculated by multiplying the slope of the equation to the $R$-value.

4.2. Storage Stability Test. The storage stability test was conducted according to ASTM D5892 to evaluate the storage stability of the polymerized asphalt binder at high temperatures. For this aim, the modified asphalt binder was filled into a tube (25 $\mathrm{mm}$ in diameter and $140 \mathrm{~mm}$ in height) and kept at the temperature of $163^{\circ} \mathrm{C}$ for $48 \mathrm{~h}$. The specimens were then kept in a freezer at a temperature of $-7^{\circ} \mathrm{C}$ for $4 \mathrm{~h}$. Afterward, the softening point tests were carried out on the asphalt binder specimens taken from the top and bottom of the tube, and the differences between the softening point of the top and bottom of the specimen were reported (Figure 3 ). This parameter should not exceed $2.2^{\circ} \mathrm{C}[19,20]$.
4.3. Multiple Stress Creep Recovery (MSCR) Test. Rutting is one of the most prevalent distresses of asphalt mixes [21, 22]. Multiple Stress Creep Recovery (MSCR) test is one of the most popular tests to evaluate the potential of the asphalt binder to resist the rutting phenomenon, especially when the asphalt binder is modified with polymers [23, 24]. The MSCR test is conducted at temperatures of 50,60 , and $70^{\circ} \mathrm{C}$ based on ASTM D7405 to evaluate the high-temperature performance of the asphalt binder $[25,26]$. For this purpose, the asphalt binder specimens were subjected to an oscillatory stress-controlled loading of $100 \mathrm{~Pa}$ for 10 cycles, followed by another 10 cycles of $3200 \mathrm{~Pa}$ loading with a loading time of one second and a recovery time of nine seconds. The average nonrecoverable creep compliance $\left(J_{\mathrm{nr}}\right)$ and the average percentage of recoverable strain $(R)$ obtained from both stages of the MSCR test are reported as the rutting parameters of the binder, which are calculated using the following equations [27]:

$$
\begin{aligned}
& J_{\mathrm{nr}}=\frac{\text { nonrecoverable strain }}{\text { stress amplitude }}, \\
& \text { recovery percentage }=\frac{\text { recovered strain }}{\text { maximum strain }} .
\end{aligned}
$$

4.4. $G^{*} / \sin \delta$ and $G^{*} \cdot \sin \delta$ Indices. Fatigue and rutting are prominent among the occurring distress of asphalt mixes 


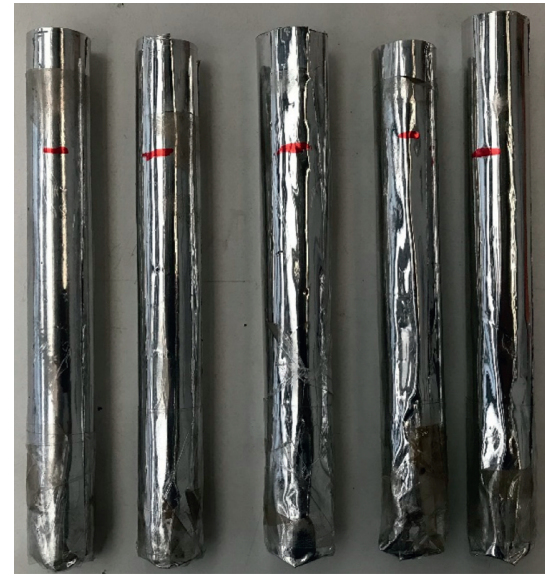

(a)

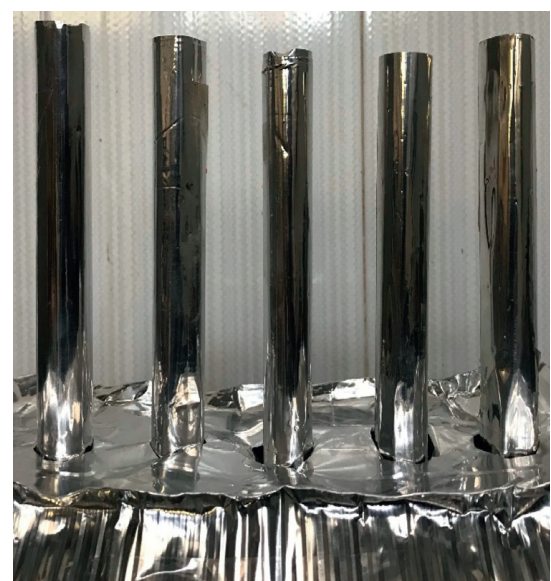

(b)

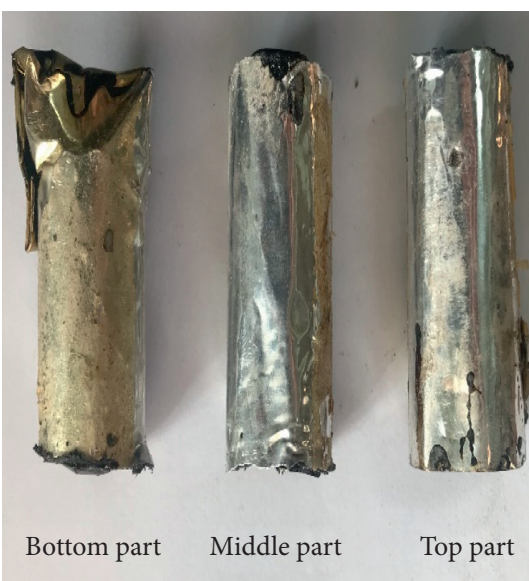

(c)

FIgURE 3: Storage stability test: (a) aluminum tubes, (b) prepared samples, and (c) three parts of the tube.

located in the moderate- and high-temperature areas $[28,29]$. The $G^{*} / \sin \delta$ and $G^{*} \cdot \sin \delta$ indices are usually considered to evaluate the asphalt binder's fatigue and rutting potential. In this research, the Dynamic Shear Rheometer (DSR) was utilized to evaluate the fatigue and rutting performance of the asphalt binder at moderate and high temperatures in accordance with AASHTO T315 [13]. The complex shear modulus $\left(G^{*}\right)$ and phase angle $(\delta)$, which are the parameters describing the rheological performance of the asphalt binder, are calculated during this evaluation [30]. The rutting performance parameter $\left(G^{*} / \sin \delta\right)$ and the fatigue resistance parameter $\left(G^{*} \cdot \sin \delta\right)$ were then calculated and reported. A higher value of $G^{*} / \sin (\delta)$ and a lower value of $G^{*} \cdot \sin (\delta)$ are favorable in terms of rutting and fatigue performance, respectively. The Superpave specifications specify a minimum value of $1.0 \mathrm{kPa}$ for the $G^{*} / \sin \delta$ of asphalt binders (unaged samples) at the high-performance grade temperature; moreover, a maximum value of $5000 \mathrm{kPa}$ is considered for $G^{*} \cdot \sin \delta$ of asphalt binders at the lowperformance grade temperature [31].

4.5. Elastic Recovery Test. The elastic recovery test is usually carried out to recognize how different polymers affect the elasticity of the polymer-modified asphalt binder [32]. In this research, in order to evaluate the effect of $C L$ on the elasticity of the asphalt binder, the elastic recovery test was carried out on the binder containing different percentages of the modifier according to AASHTO T301 [33]. For that test, the asphalt binder samples were stretched at a speed of $5 \mathrm{~cm} /$ min in a water bath; meanwhile, the water bath temperature was constant at $25^{\circ} \mathrm{C}$ (Figure 4). Samples were cut from the middle when specimens were stretched to $10 \mathrm{~cm}$. Then, the length of the samples was measured after $30 \mathrm{~min}$ and $60 \mathrm{~min}$, respectively. The elastic recovery was determined using the following equation:

$$
\text { elastic recovery percentage }=\left(\frac{10-L}{10}\right) 100,
$$

where $L(\mathrm{~cm})$ presents the measured length of the sample (30 and $60 \mathrm{~min}$ after cutting that in half).

\section{Results and Discussion}

5.1. Conventional Asphalt Binder Tests Result. The results of the penetration, softening point, kinematic viscosity, and ductility are summarized in Table 4 . For each sample, the reported value was obtained by averaging the values of three replicates. As can be seen in Table 4, the softening point increases by increasing the CL content in the asphalt binder, which shows that the temperature sensitivity of the asphalt binder decreases by increasing the CL content. Increasing the CL content also reduces the penetration values, and the stiffness of the asphalt binder increases by adding the CL material into the asphalt binder. The ductility, which is the adhesion parameter, reduces by adding CL powder into the asphalt binder. According to previous studies, the kraft lignin also dwindled the penetration degree and increased the modified asphalt binder's hardness [13]. The viscosity of the asphalt binder increases by almost $50 \%$ when the $\mathrm{CL}$ content is increased. The increase of viscosity may result in a dramatic increase in the mixing and compaction temperature of the asphalt mixes. In the present study, the viscosity of the asphalt binder containing different amounts of the $\mathrm{CL}$ material at $165^{\circ} \mathrm{C}$ and $135^{\circ} \mathrm{C}$ was measured using the rotational viscosity method to investigate the pumpability, mixability, and workability of the CL-modified asphalt binder.

The results of the rotational viscosity are presented in Figure 5. As can be observed, the viscosity of all modified asphalt binders experiences an upward trend by increasing the CL content, which will be challenging for pumpability and workability during the asphalt construction process. This is the same result as $\mathrm{Xu}$ et al. and Gao et al. reported about the effect of lignin on the asphalt binder's viscosity $[7,8]$. Moreover, to analyze the significance of the presence of CL within the asphalt binder on the rotational viscosity, a one-way analysis of variance (ANOVA) was conducted. The results of one-way ANOVA performed using Minitab software are presented in Table 5. The null hypothesis that was all means are equal was assumed for the statistical analysis. It can be found that the $p$ value was less than 0.05 


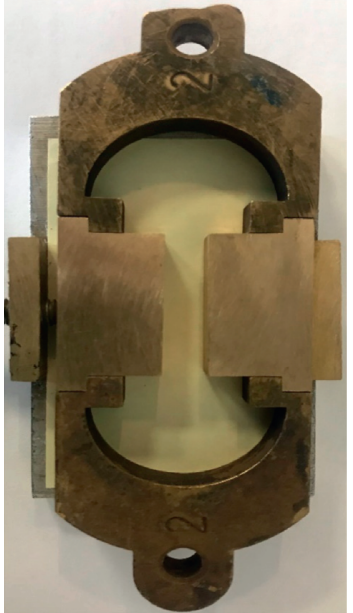

(a)

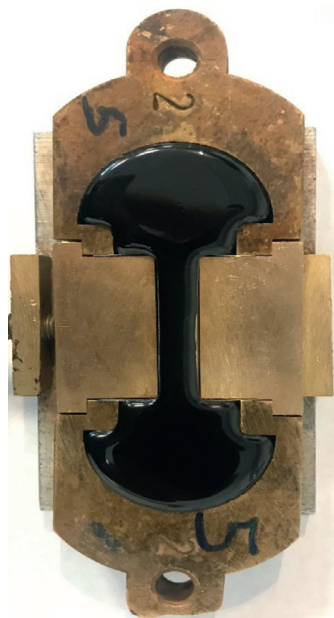

(b)

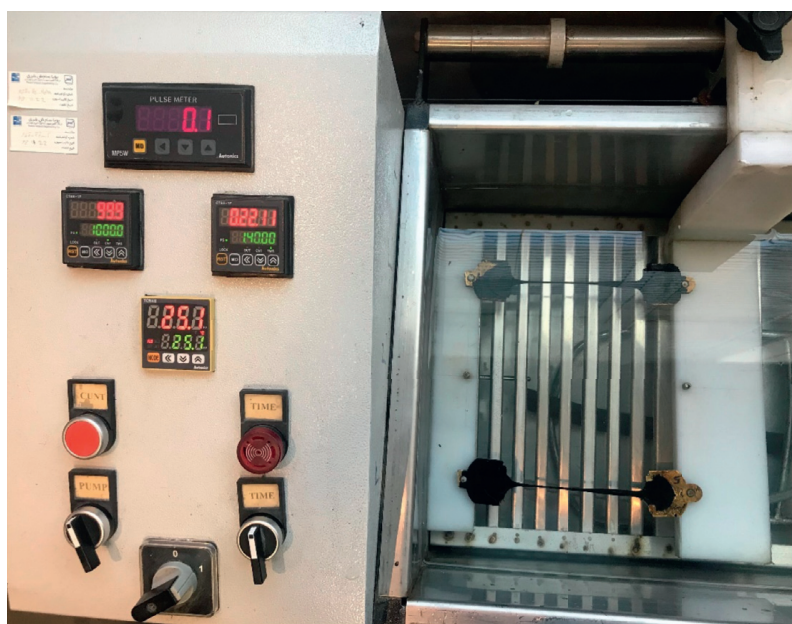

(c)

FIGURE 4: Elastic recovery test: (a) sample mold, (b) prepared sample, and (c) elastic recovery test apparatus.

TABLE 4: The conventional asphalt binder test results.

\begin{tabular}{lcccc}
\hline CL content (\%) & Softening point $\left({ }^{\circ} \mathrm{C}\right)$ & Penetration at $25^{\circ} \mathrm{C}(0.1 \mathrm{~mm})$ & Kinematic viscosity at $135^{\circ} \mathrm{C}(\mathrm{cSt})$ & Ductility $(\mathrm{cm})$ \\
\hline 0 & 48.6 & 62.5 & 339 & 408 \\
5 & 50.1 & 55.4 & 431 & 132 \\
10 & 51.1 & 52 & 548 & 127 \\
15 & 52.2 & 46 & 617 & 116 \\
20 & 53 & 42.6 & 104 \\
\hline
\end{tabular}

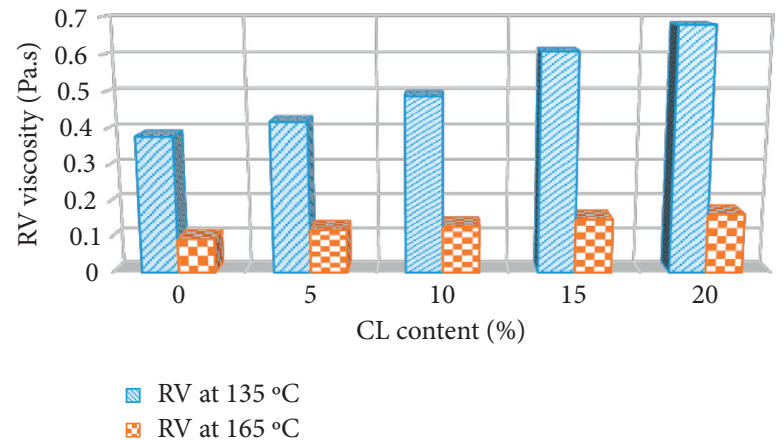

Figure 5: The rotational viscosity test results.

TABLE 5: One-way ANOVA: rotational viscosity values versus CL content.

\begin{tabular}{cccccc}
\hline Source & DF & Adj SS & Adj MS & $F$-value & $P$ value \\
\hline$R V$ values at $135^{\circ} \mathrm{C}(\mathrm{mPa} \cdot \mathrm{s})$ & & & \\
CL content & 4 & 190500 & 47625.1 & 110.43 & 0.000 \\
Error & 10 & 4313 & 431.3 & & \\
Total & 14 & 194813 & & & \\
\hline$R V$ values at $165^{\circ} \mathrm{C}(\mathrm{mPa} \cdot \mathrm{s})$ & & & \\
$\mathrm{CL}$ content & 4 & 8499.7 & 2124.9 & 42.33 & 0.000 \\
Error & 10 & 502 & 50.20 & & \\
Total & 14 & 9001.7 & & & \\
\hline
\end{tabular}

for both temperatures; therefore, the null hypothesis was rejected. Meanwhile, the Tukey method with a 95\% confidence level was considered for ranking the asphalt binder's viscosity values at two temperatures. Based on Table 6 , it can be concluded that the specimens containing 20\% CL had the highest values of rotational viscosity at both temperatures.

Table 7 illustrates the Arrhenius equation of five different types of samples on the basis of two different temperatures $\left(135^{\circ} \mathrm{C}\right.$ and $\left.165^{\circ} \mathrm{C}\right)$. The results of flow activation energy are also calculated and depicted in Figure 6. As can be seen in the figure, the activation energy decreases dramatically when 5\% of the CL material is added to the asphalt binder. However, by increasing the CL content, the activation energy goes up until it becomes just higher than the activation energy of the virgin asphalt binder. In other words, the temperature susceptibility of the binder increases when $5 \%$ of the $\mathrm{CL}$ material is added to the binder. This phenomenon may be due to the puffy structure of the binder resulting from adding the $\mathrm{CL}$ material. However, adding more CL 
TABLE 6: Grouping information using the Tukey method and 95\% confidence interval.

\begin{tabular}{ccccc}
\hline CL content (\%) & $N$ & Mean & & Grouping \\
\hline$R V$ values at $135^{\circ} \mathrm{C}(\mathrm{mPa} \cdot \mathrm{s})$ & & & & $\mathrm{B}$ \\
20 & 3 & 678.0 & $\mathrm{~A}$ & $\mathrm{C}$ \\
15 & 3 & 621.7 & & $\mathrm{D}$ \\
10 & 3 & 493.3 & & $\mathrm{D}$ \\
5 & 3 & 420.7 & & \\
0 & 3 & 380.7 & $\mathrm{~A}$ & $\mathrm{~B}$ \\
\hline$R V$ values at $165^{\circ} \mathrm{C}(\mathrm{mPa} \cdot \mathrm{s})$ & 3 & & $\mathrm{~A}$ & $\mathrm{~B}$ \\
20 & 3 & 164.0 & & $\mathrm{C}$ \\
15 & 3 & 151.3 & 128.7 & \\
\hline
\end{tabular}

TABLE 7: Fitted equations for the plot of $\ln \eta$ versus $1 / T$.

\begin{tabular}{|c|c|c|c|c|c|c|}
\hline CL content $(\%)$ & $N$ & Mean $\ln \eta\left(135^{\circ} \mathrm{C}\right)$ & Mean $\ln \eta\left(165^{\circ} \mathrm{C}\right)$ & $1 / T(1 / \mathrm{K})$ & $1 / T(1 / \mathrm{K})$ & Fitted equation \\
\hline 0 & 3 & -0.966 & -2.343 & 0.00245 & 0.00228 & $y=8100 x-20.811$ \\
\hline 5 & 3 & -0.866 & -2.115 & 0.00245 & 0.00228 & $y=7348.2 x-18.869$ \\
\hline 10 & 3 & -0.707 & -2.05 & 0.00245 & 0.00228 & $y=7902.4 x-20.067$ \\
\hline 15 & 3 & -0.475 & -1.888 & 0.00245 & 0.00228 & $y=8310 x-20.835$ \\
\hline 20 & 3 & -0.389 & -1.808 & 0.00245 & 0.00228 & $y=8347.1 x-20.83$ \\
\hline
\end{tabular}

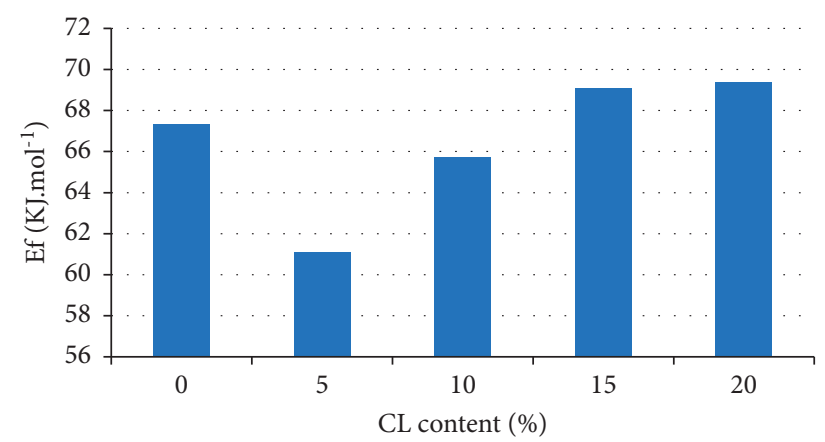

Figure 6: The activation energy of the asphalt binder containing different percentages of CL.

compensates for this defect, and the activation energy becomes almost as high as the neat binder when $15 \%$ to $20 \%$ of the CL material is added. Various studies have indicated that using different types of lignin as an asphalt binder modifier enhanced the flow activation energy; however, there have been limited studies on the effect of CL on the asphalt binder's flow activation energy $[8,13]$.

5.2. Storage Stability Test Result. The results of the storage stability test are presented in Table 8 . If the differences between the softening point of the top and down of the specimen become more than $2.2^{\circ} \mathrm{C}$, the modified asphalt cannot be stored, and its usage will encounter many problems [34]. It can be seen from the results that the storage stability values are less than the threshold as mentioned above; thus using $20 \%$ of the CL does not have any substantial adverse effect on the storage stability of the asphalt binder. Yu et al., in their study, revealed that the dispersion of soda lignin powder in the asphalt binder was comparatively uniform and stable, which led to excellent thermal storage stability of modified specimens [13].
5.3. Multiple Stress Creep Recovery (MSCR) Test Result. The results of the MSCR test are presented in the bar charts of Figures 7-10. As can be seen, the Jnr value declines by increasing the amount of CL at both stress levels of 0.1 and $3.2 \mathrm{kPa}$. Hence, it can be concluded that the rutting resistance of the asphalt binder improves when the amount of CL increases in the binder.

It is also indicated that adding CL leads to an incremental increase in the recovery percentage of the asphalt binder, especially at a stress level of $3.2 \mathrm{kPa}$. This performance shows that using the CL in the asphalt binder brings an increase in the elasticity of the modified samples and subsequently can improve the rutting performance. Comparing the results at different temperatures shows that the same trend has happened for all three studied temperatures. The present results in this section are compatible with the study of Arafat et al., which indicated that kraft lignin improved the rutting performance of asphalt binders [2]. A similar finding was presented by Yu et al., which illustrated that using soda lignin powder for asphalt binder modification increased the restored recovery values [13]. As 
TABLE 8: The results of the storage stability test.

\begin{tabular}{lccc}
\hline CL content $(\%)$ & Softening point of down $\left({ }^{\circ} \mathrm{C}\right)$ & Softening point of top $\left({ }^{\circ} \mathrm{C}\right)$ & Softening point differences $\left({ }^{\circ} \mathrm{C}\right)$ \\
\hline 0 & 49.7 & 49.5 & 0.2 \\
5 & 50.7 & 50.4 & 0.3 \\
10 & 51.1 & 50.9 & 0.2 \\
15 & 51.9 & 51.5 & 0.4 \\
20 & 53.5 & 53.1 & 0.4 \\
\hline
\end{tabular}

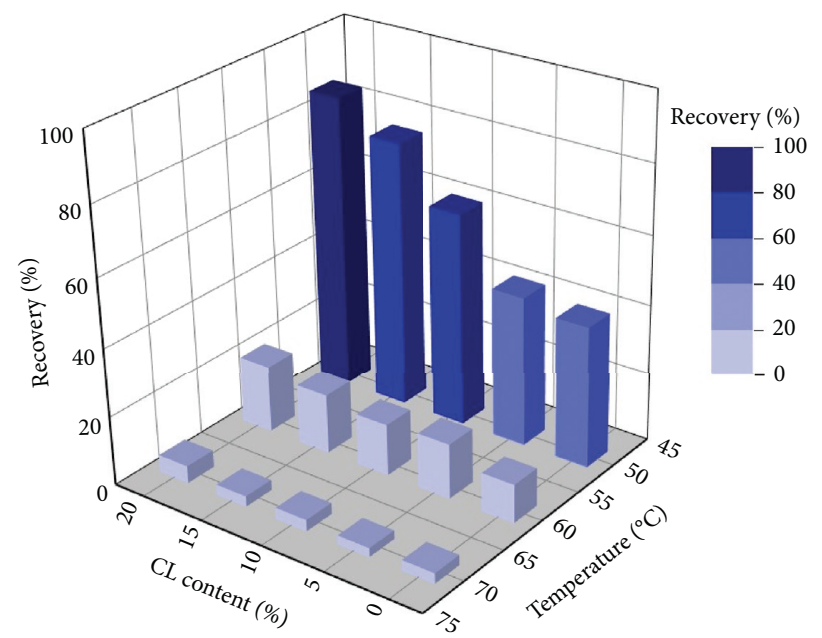

Figure 7: Variations in the percent recovery $R$ at different test conditions under $0.1 \mathrm{kPa}$ stress level.

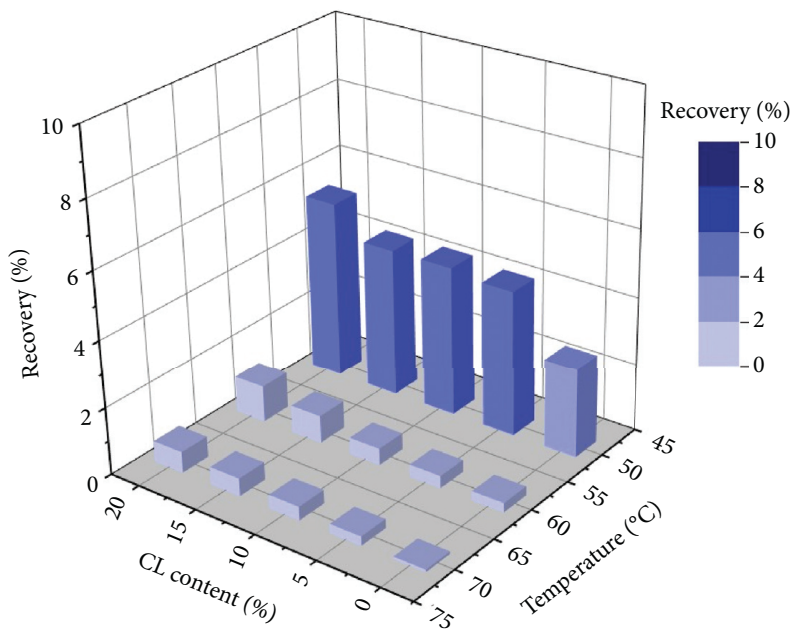

Figure 8: Variations in the percent recovery $R$ at different test conditions under $3.2 \mathrm{kPa}$ stress level.

illustrated in this study, it is worth mentioning that the utilization of CL as an asphalt binder modifier can further improve the rutting resistance and elastic recovery of asphalt binders.

5.4. $G^{*} / \sin \delta$ and $G^{*} \cdot \sin \delta$ Indices. The results of the rutting performance at moderate and high temperatures are depicted in Figures 11 and 12. Figure 11 shows the calculated values of the $G^{*} / \sin (\delta)$ parameter at temperatures of 50,60 , and $70^{\circ} \mathrm{C}$. It is worth mentioning that the temperature ranging from $50^{\circ} \mathrm{C}$ to $70^{\circ} \mathrm{C}$ was considered to simulate the high-temperature region [35]. It can be seen that using up to $15 \%$ of the CL additive can improve the rutting performance of the asphalt binder incrementally. Almost 70\% improvement in the rutting parameter is observed when $15 \%$ of the CL material is added to the neat asphalt binder.

On the other hand, the rutting parameter falls by almost $15 \%$ when the CL content increases from $15 \%$ to $20 \%$; however, it is still higher than the rutting parameter of the neat asphalt binder. The same trend is seen at all studied temperatures. Comparing the results of the rutting parameter at different temperatures show that the rutting 


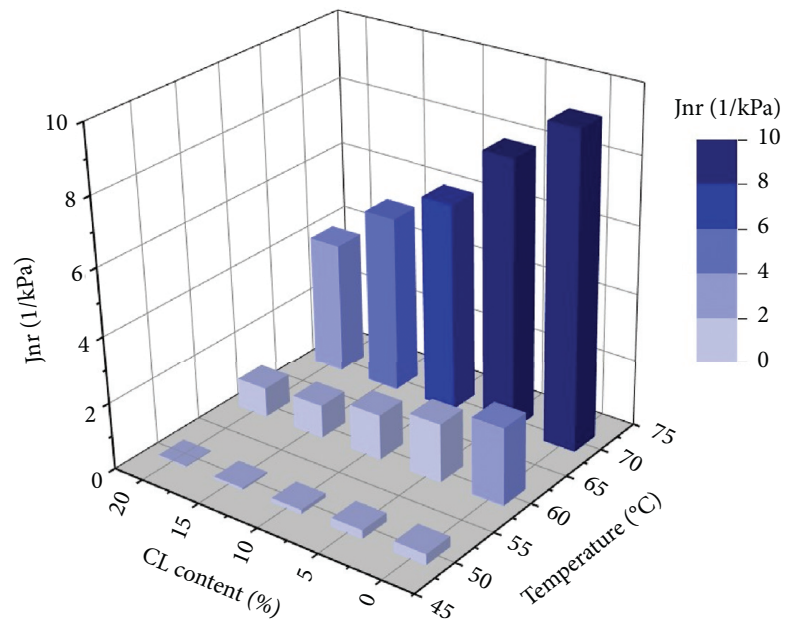

FIgURE 9: Variations in the nonrecoverable creep compliance $\left(J_{\mathrm{nr}}\right)$ at different test conditions under $0.1 \mathrm{kPa}$ stress level.

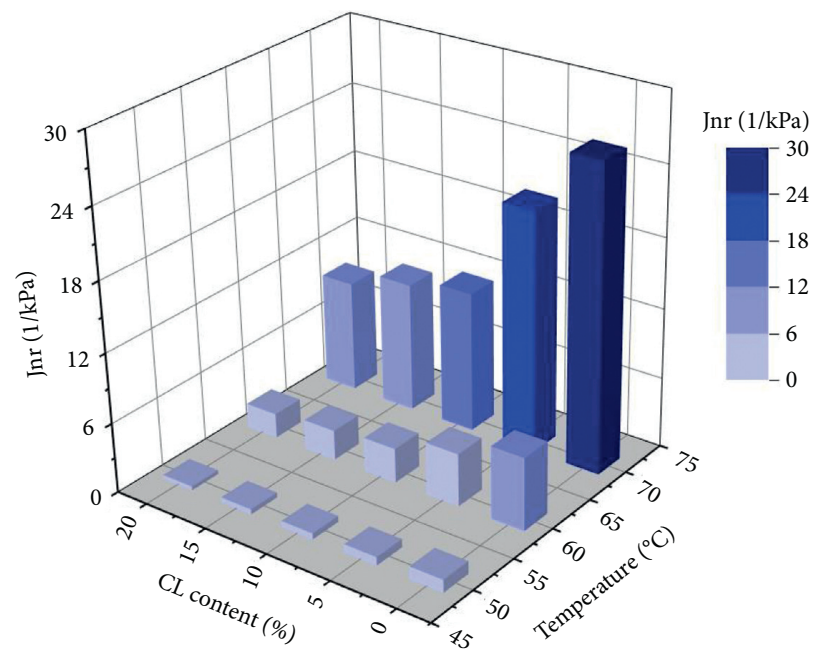

FIGURE 10: Variations in the nonrecoverable creep compliance $\left(J_{\mathrm{nr}}\right)$ at different test conditions under $3.2 \mathrm{kPa}$ stress level.

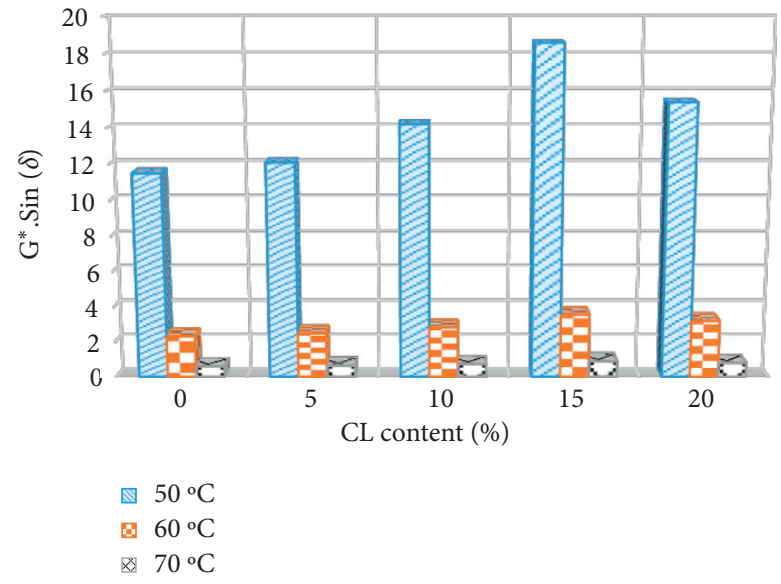

FIGURE 11: The results of $G^{*} / \sin (\delta)$ parameter at high-level temperatures. 


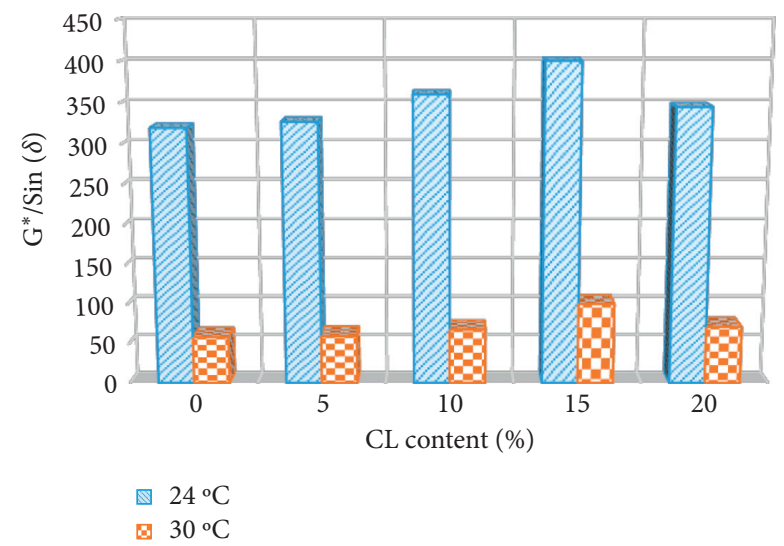

Figure 12: The results of $G^{*} \cdot \sin (\delta)$ parameter at temperatures of $24^{\circ} \mathrm{C}$ and $30^{\circ} \mathrm{C}$.

parameter declines dramatically when the temperature increases by $10^{\circ} \mathrm{C}$ from $50^{\circ} \mathrm{C}$ to $60^{\circ} \mathrm{C}$. Moreover, the sensitivity of all asphalt binder samples to temperature is almost equal.

The fatigue analysis was performed based on the lowmoderate temperature region (ranging from $24^{\circ} \mathrm{C}$ to $\left.30^{\circ} \mathrm{C}\right)$ [35]. Figure 12 shows the results of $G^{*} \cdot \sin (\delta)$ at $24^{\circ} \mathrm{C}$ and $30^{\circ} \mathrm{C} . G^{*} \cdot \sin (\delta)$ is the parameter for the fatigue resistance of the asphalt binder at intermediate temperatures [36]. It can be observed that increasing the amount of the CL to $15 \%$ in the asphalt binder leads to an almost $25 \%$ increase in the $G^{*} \cdot \sin (\delta)$ parameter at both studied temperatures. This performance indicates that the fatigue resistance of the asphalt binder declines slightly by increasing the CL content. This performance can be due to the stiffening effect of the CL on the asphalt binder, which can make it brittle and less resistant to fatigue. A similar trend can be observed at both studied temperatures. Norgbey et al., in their study, revealed that the addition of lignin powder into the virgin asphalt binder enhanced the rutting resistance properties of modified samples, which is consistent with the results of this study [9]. Also, Gao et al. indicated that the fatigue strength of the asphalt binder degraded as a result of adding lignin [8]. The results of $G^{*} \cdot \sin (\delta)$ in this study bring the same results about the effect of CL on the asphalt binder fatigue life.

5.5. Elastic Recovery Test Result. The results of the elastic recovery test are presented in Figure 13. The recovery percentage is calculated after 30 and 60 minutes of cutting the asphalt binder in a $25^{\circ} \mathrm{C}$ water bath. As can be seen, the main proportion of the recovery occurs in the first thirty minutes, and from the thirtieth to the sixtieth minute after cutting the sample, a small amount of the sample's length is recovered. The recovery percentage declines substantially by adding CL. Therefore, the elasticity of the binder decreases when the CL is increased, and adding $10 \%$ and $20 \%$ of the CL leads to a $40 \%$ and $87 \%$ reduction in the elastic recovery, respectively. This performance can provide an adverse effect on the fatigue and cracking performance of the asphalt binder.

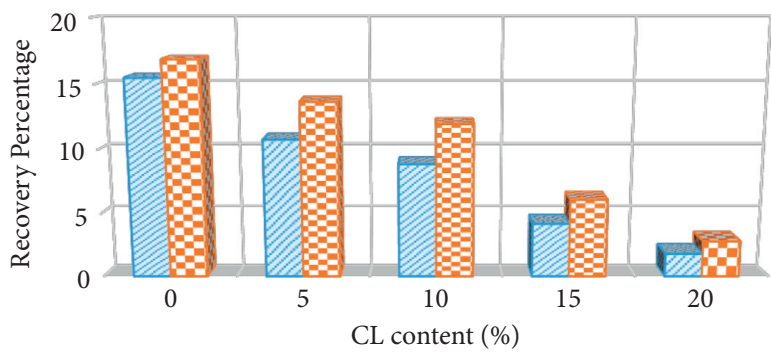

Recovery percentage after 30 mins
Recovery percentage after 60 mins

Figure 13: The elastic recovery test results.

\section{Conclusions}

In this study, the effect of calcium lignosulfonate as a waste by-product of the wood industry on the performance properties of asphalt binder was investigated through the MSCR, and elastic recovery tests. In addition, the values of $G^{*} / \sin (\delta)$ and $G^{*} \cdot \sin (\delta)$ were determined. The study conclusions are as follows:

(i) The FESEM test results indicated that the CL modification formed the asphalt binder texture spongy and porous, which positively affected the elasticity performance of CL-modified asphalt binders.

(ii) The conventional test results showed that the viscosity and softening point of the asphalt binder increased, and the penetration declined by increasing the CL content, which emanated from the stiffening effect of the CL powder on the asphalt binder.

(iii) The rotational viscosity test showed that adding CL into the binder will be challenging for mixing and compacting the asphalt mixes.

(iv) The dispersion of CL into the asphalt binder cannot adversely affect the thermal storage stability of the modified asphalt binder. Then, CL-modified 
asphalt binders can be considered uniform and stable for storage at high-temperature conditions.

(v) The MSCR results showed that the percent recovery and the nonrecoverable creep compliance improved by increasing the CL content in the asphalt binder at high temperatures, which led to rutting resistance enhancement for CL-modified asphalt binders.

(vi) The $G^{*} / \sin (\delta)$ parameter approved the results of the MSCR test and showed that the presence of CL within the asphalt binder improved the rutting resistance of asphalt binders. The rutting performance improved with CL content until it reached the most at $15 \%$. More CL content affected the rutting performance decline. However, in comparison to the rutting performance of the control sample, it was enhanced at all CL contents used in this study.

(vii) Because of the stiffening effect of the CL on the asphalt binder, the $G^{*} \cdot \sin (\delta)$ parameter increased slightly by increasing the CL content in the asphalt binder, which showed an increase in brittleness of asphalt binders leading to the fatigue performance degradation.

(viii) The elastic recovery test results showed that adding CL powder led to a significant decrease in the elasticity of the asphalt binder, which led to fatigue life degradation. Among the four types of asphalt binders prepared by 5\%, 10\%, 15\%, and $20 \%$ of CL, the asphalt binder with $20 \% \mathrm{CL}$ was more prone to cracking because it had the least elastic recovery values. The high sensitivity to cracking can lead to reflecting cracks propagation through asphalt pavement layers.

\section{Data Availability}

At present, the data used to substantiate and corroborate the conclusions of this research are under prohibition because of restrictions and privacy rules. Three months after the publication of this research, the corresponding author will be able to consider the requests for outputs.

\section{Conflicts of Interest}

The authors declare that there are no conflicts of interest regarding the publication of this paper.

\section{References}

[1] A. Tribot, G. Amer, M. Abdou Alio et al., "Wood-lignin: supply, extraction processes and use as bio-based material," European Polymer Journal, vol. 112, pp. 228-240, 2019.

[2] S. Arafat, N. Kumar, N. M. Wasiuddin, E. O. Owhe, and J. G. Lynam, "Sustainable lignin to enhance asphalt binder oxidative aging properties and mix properties," Journal of Cleaner Production, vol. 217, pp. 456-468, 2019.

[3] F. Zhu, J. Li, W. Jiang, S. Zhang, and W. Dong, "Freeze-thaw performance of silt sand treated with lignin," Advances in
Civil Engineering, vol. 2021, Article ID 6639268, 10 pages, 2021.

[4] D. S. Bajwa, G. Pourhashem, A. H. Ullah, and S. G. Bajwa, "A concise review of current lignin production, applications, products and their environmental impact," Industrial Crops and Products, vol. 139, Article ID 111526, 2019.

[5] M. S. Karunarathna and R. C. Smith, "Valorization of lignin as a sustainable component of structural materials and composites: advances from 2011 to 2019," Sustainability, vol. 12, no. 2, p. 734, 2020.

[6] H. Wang and K. Derewecki, "Rheological properties of asphalt binder partially substituted with wood lignin," in Proceedings of the 2013 Airfield \& Highway Pavement Conference, pp. 977-986, Los Angeles, CA, USA, June 2013.

[7] G. Xu, H. Wang, and H. Zhu, "Rheological properties and anti-aging performance of asphalt binder modified with wood lignin," Construction and Building Materials, vol. 151, pp. 801-808, 2017.

[8] J. Gao, H. Wang, C. Liu, D. Ge, Z. You, and M. Yu, "Hightemperature rheological behavior and fatigue performance of lignin modified asphalt binder," Construction and Building Materials, vol. 230, Article ID 117063, 2020.

[9] E. Norgbey, J. Huang, V. Hirsch et al., "Unravelling the efficient use of waste lignin as a bitumen modifier for sustainable roads," Construction and Building Materials, vol. 230, Article ID 116957, 2020.

[10] K. B. Batista, R. P. L. Padilha, T. O. Castro et al., "Hightemperature, low-temperature and weathering aging performance of lignin modified asphalt binders," Industrial Crops and Products, vol. 111, pp. 107-116, 2018.

[11] N. S. McCready and R. C. Williams, "Utilization of biofuel coproducts as performance enhancers in asphalt binder," Transportation Research Record: Journal of the Transportation Research Board, vol. 2051, no. 1, pp. 8-14, 2008.

[12] A. Grossman and W. Vermerris, "Lignin-based polymers and nanomaterials," Current Opinion in Biotechnology, vol. 56, pp. 112-120, 2019.

[13] J. Yu, M. Vaidya, G. Su, S. Adhikari, E. Korolev, and S. Shekhovtsova, "Experimental study of soda lignin powder as an asphalt modifier for a sustainable pavement material," Construction and Building Materials, vol. 298, Article ID 123884, 2021.

[14] C. A. Strydom, T. S. Mthombo, J. R. Bunt, and H. W. J. P. Neomagus, "Some physical and chemical characteristics of calcium lignosulphonate-bound coal fines," Journal of the Southern African Institute of Mining and Metallurgy, vol. 118, no. 12, pp. 1277-1283, 2018.

[15] I. Z. Yildirim and M. Prezzi, "Chemical, mineralogical, and morphological properties of steel slag," Advances in Civil Engineering, vol. 2011, Article ID 463638, 13 pages, 2011.

[16] M. Sabouri, D. Mirzaiyan, and A. Moniri, "Effectiveness of Linear Amplitude Sweep (LAS) asphalt binder test in predicting asphalt mixtures fatigue performance," Construction and Building Materials, vol. 171, pp. 281-290, 2018.

[17] C. Yang, J. Xie, S. Wu et al., "Investigation of physicochemical and rheological properties of SARA components separated from bitumen," Construction and Building Materials, vol. 235, Article ID 117437, 2020.

[18] H. Zhai and D. Salomon, "Ranking asphalt binders by activation energy for flow want more papers like this? ranking asphalt binders by activation energy for flow," 2002, https://www. academia.edu/download/35875205/Ranking-Asphalt-Binders-byActivation-Energy-for-Flow-J.Asphalt-Binder-Rheology.pdf. 
[19] S. S. Galooyak, B. Dabir, A. E. Nazarbeygi, and A. Moeini, "Rheological properties and storage stability of bitumen/SBS/ montmorillonite composites," Construction and Building Materials, vol. 24, no. 3, pp. 300-307, 2010.

[20] S. Nizamuddin, M. Jamal, J. Santos, and F. Giustozzi, "Recycling of low-value packaging films in bitumen blends: a grey-based multi criteria decision making approach considering a set of laboratory performance and environmental impact indicators," Science of the Total Environment, vol. 778, Article ID 146187, 2021.

[21] H. Ziari, Y. Saghafi, A. Moniri, and P. Bahri, "The effect of polyolefin-aramid fibers on performance of hot mix asphalt," Petroleum Science and Technology, vol. 38, no. 3, pp. 170-176, 2020.

[22] X. Yan, R. Ying, J. Jin, and Y. Zhang, "Study on cracking resistance of basalt fiber-reinforced microbond asphalt macadam," Advances in Civil Engineering, vol. 2021, Article ID 6647766, 9 pages, 2021.

[23] X.-y. Liu, P. Wang, Y. Lu, T.-t. Zhang, L.-z. Wang, and T.-f. Wang, "Identifying the thermal storage stability of polymer-modified asphalt with carbon nanotubes based on its macroperformance and micromorphology," Advances in Materials Science and Engineering, vol. 2021, Article ID 6637999, 17 pages, 2021.

[24] N. Saboo and A. Mudgal, "Modelling creep and recovery response of asphalt binders using generalized burgers model," Petroleum Science and Technology, vol. 36, no. 20, pp. 16271634, 2018.

[25] J. Zhang, L. F. Walubita, A. N. M. Faruk, P. Karki, and G. S. Simate, "Use of the MSCR test to characterize the asphalt binder properties relative to HMA rutting performance - a laboratory study," Construction and Building Materials, vol. 94, pp. 218-227, 2015.

[26] A. Behnood and J. Olek, "Stress-dependent behavior and rutting resistance of modified asphalt binders: an MSCR approach," Construction and Building Materials, vol. 157, pp. 635-646, 2017.

[27] H. H. Kim, M. Mazumder, M.-S. Lee, and S.-J. Lee, "Evaluation of high-performance asphalt binders modified with SBS, SIS, and GTR," Advances in Civil Engineering, vol. 2019, pp. 1-11, 2019.

[28] H. Ziari, A. Moniri, and N. Norouzi, "The effect of nanoclay as bitumen modifier on rutting performance of asphalt mixtures containing high content of rejuvenated reclaimed asphalt pavement," Petroleum Science and Technology, vol. 37, no. 17, pp. 1946-1951, 2019.

[29] A. Bensaada, K. Soudani, and S. Haddadi, "Effects of shortterm aging on the physical and rheological properties of plastic waste-modified bitumen," Innovative Infrastructure Solutions, vol. 6, no. 3, p. 135, 2021.

[30] Z. H. Al-Saffar, H. Yaacob, M. K. I. M. Satar et al., "Effects of maltene on the attributes of reclaimed asphalt pavement: performance optimisation," Construction and Building Materials, vol. 302, Article ID 124210, 2021.

[31] E. H. Fini, D. Oldham, F. S. Buabeng, and S. H. Nezhad, "Investigating the aging susceptibility of bio-modified asphalts," in Proceedings of the Airfield and Highway Pavements 2015, pp. 62-73, Miami, FA, USA, June 2015.

[32] E. Baskent Aydemir and M. H. Ozkul, "Investigation of effect of bitumen chemical composition, elastomeric polymer and paraffin wax additives on the properties of bitumen by using response surface method," Construction and Building Materials, vol. 234, 2020.
[33] R. Moraes, D. Swiertz, and H. Bahia, "Comparison of new test methods and new specifications for rutting resistance and elasticity of modified binders," in Proceedings of the 62nd Canadian Technical Asphalt Association (CTAA) Annual Conference, vol. 5, pp. 203-223, Halifax, Canada, November 2017, https://www.researchgate.net/publication/324877373.

[34] F. J. Navarro, P. Partal, F. Martínez-Boza, and C. Gallegos, "Thermo-rheological behaviour and storage stability of ground tire rubber-modified bitumens," Fuel, vol. 83, no. 1415, pp. 2041-2049, 2004.

[35] C. Zhang, J. Yu, T. Wang, S. Xu, C. Hu, and W. Duan, "Evaluation of ultraviolet aging resistance of bitumen modified with isobutyltriethoxysilane surface organic grafted LDH," Construction and Building Materials, vol. 241, 2020.

[36] A. H. Ali, N. S. Mashaan, and M. R. Karim, "Investigations of physical and rheological properties of aged rubberised bitumen," Annals of Materials Science \& Engineering, vol. 2013, Article ID 239036, 7 pages, 2013. 